\title{
Parents of Children with Disabililties in Swaziland Challenges and Resources in a Resilience Perspective
}

\author{
S,K. Thwala*, Arve Gunnestad, I. Dludlu, \\ Swaziland
}

*Corresponding Author: S, K. Thwala, Swaziland

\begin{abstract}
This article explores how resilience is built into everyday life and how protective factors are used as tools of resilience by parents of children living with disabilities in Swaziland with particular attention given to challenges and resources as forms of resilience. Participants were parents who were purposively sampled from three regions whose children attended in 3 special primary schools in the same regions. Data were collected using focus group discussions and individual interviews and were thematically analysed. The findings revealed that parents of children with disabilities were not equipped on how to cope with their children's disability. The findings suggest the need for the development of training programmes for teachers and health personnel on how to counsel and work with parents of children with disabilities in order to help them in understanding their own feelings and apply coping strategies.
\end{abstract}

Keywords: Challenges, Disabilities, Experiences, Parents, Protective Factors, Resilience, Resources, Swaziland

\section{INTRODUCTION}

This article explores how resilience is built into everyday life of parents of children with disabilities and how resources and challenges are used as tools of resilience by parents of children with disabilities in Swaziland. Parents of children with disabilities are confronted with numerous and distinctive social and psychological challenges in dealing with their roles as caregivers to their children (Lewis \&Doorlag, 2006; Giffing, 2009; Dobson, Middleton \&Beardworth, 2001) Such challenges appear to have serious and multiple implications on the nature and quality of their caregiving (Heiman, 2002; Blew \& Kenny, 2006). Dobson, Middleton and Beardworth (2001) assert that living with a child with disabilities can have profound effects on the entire family: parents, siblings and extended family members. It is a unique shared experience for families and can affect all aspects of family functioning. On the positive side, it can broaden horizons, increase family members' awareness of their inner strength, enhance family cohesion, and encourage connections to community groups or religious institutions. On the negative side one might find that care for a child with disability can take all the energy of the parents. Siblings may feel neglected, and the spouses may have too little time to grow their mutual relationship.

In the case of parents, the birth of a child with disabilities or the discovery that a child has disability is an intense and traumatic event. When it is learned at birth that the child has disability, the effect on the parents can be devastating. Their initial reaction may be numbness. This is followed by a period of questioning which may go on for many years, as to why this should have happened to them. The parents may tend to blame themselves or each other (Scorgie\&Sobsey, 2000). Some experience considerable stress, as well as feelings of depression, anger, shock, denial, self-blames guilt and confusion (Heiman, 2002). Therefore, the sequence and time needed for adjustment is different for every parent.

While many studies (Beardworth 2001; Heiman, 2002; Blew \& Kenny 2006) have researched teacher experiences in teaching children with Special Educational Needs (SENs), no rigorous study has examined the experiences of parents with such childrenin an African setting. The majority of studies that investigated about the experiences of families and parents of such children were done mainly in European countries, United States of America, Australia and some Asian countries. Several in-depth qualitative and even quantitative studies have been carried out in relation to parents' perceptions. 
Most of these studies provided significant information about the challenges parents face in raising their children living with disabilities in their own context. Based on these studies this article intends to add to the very small body of research which prioritizes the general and lived experiences of parents of these children in Africa, specifically in Swaziland. The article also examines challenges these parents face in bringing up their children.

The following research questions were posed to guide the study: $i)$ what are the experiences parents of children living with disabilities undergo in raising their children? ii) What are the challenges parents of children with disabilities encounter in bringing up their children? iii) What are protective factors that help them to cope?

\section{RESILIENCE THEORY}

This study is making use of resilience theory. The definition of resilience may be contentious as the term may be defined from different angles by different authors. Gunnestad (2003) asserts that it is a concept from physics; it refers to the ability of a material to regain its former shape after being stretched, bent or twisted. Applied on human beings it is the ability to recover after crisis, to function well in difficult situations, to cope with stress. According to ÖzlemÖgtem-Young,(2018) it suggests the ability and capacity of systems, organisations, individuals, cities, communities, or societies to 'bounce back' and be able to maintain their core functioning; adapting positively in the face of a straining or adverse condition. The concept of resilience is prevalent and adopted widely in the discourses of policymakers and policy, and is usually seen as a process or outcome which results from facing and responding to adversity in the form of extraordinary and large-scale events. Researchers who examine the concept of resilience concur that resilience is a process, rather than astatic construct (Masten, 2001; Richardson, 2002).Fergus and Zimmerman (2005) argue that resilience is defined by context and that resilience theory recognises the role of external context and contextual factors including social and environmental influence

Mampane and Bouwer (2011) view resilience as having a disposition to identify and utilise personal capacities, competencies (strengths) and assets in a specific context when faced with perceived adverse situations. The interaction between the individual and the context leads to behaviour that elicits sustained constructive outcomes that include continuous learning (growing and renewing) and flexibly negotiating the situation. Theron and Theron (2010) state that although researchers accept that there are universal mechanisms of resilience, such as positive attachments, agency and mastery, intelligence, meaning making and self-regulation, they caution that the ways in which these processes operate will probably be unique across cultural contexts

Gunnestad (2006) emphasised on protective factors as key elements of resilience. He conducted a study among students in Swaziland, Zambia and Norway where students did report about a period of crisis in their lives. He found a number of serious situations like sickness, death of close relative, accidents, mockery, abuse and also getting a disabled brother/sister. Then he asked the informants to reflect on what helped them to go through and get out of the hardship. He was, however, interested to find out what makes people to cope in difficulties. Through the about 90 responses from the students in his study and by reading a number of other international studies, he was able to identify 3 groups of protective factors. A protective factor is factor that reduces or mitigates the effect of risk factors or difficulties in the life of a person. The three groups of protective factors were: 1. Network factors social support, 2. Abilities and skills, 3. Cultural and existential support - meaning values and faith.

Network means people the person are in touch with on a reasonable regular basis. It means family, relatives, friends, neighbours, and others. In a crisis the network can give moral support, practical support, advice on what to do, financial support etc. In almost all situations of coping in crises, network support has been an important protective factor.

Abilities and skills refer to the resources in the person him- or herself. It is inborn abilities like intelligence, temper, robustness and others, and learned skills like social skills, practical skills, communication skills, skills in music and art etc. Abilities and skills influence the ability to cope by building a positive self-image, and making people to think that I am able, I can handle this situation. It also makes the person attractive to friends, and in that way strengthens the network effect.

Cultural and existential support is the third group of protective factors that was important in many of the international studies. It implied how you understand and think of the situation you are in. It makes 
a great difference if you think that your disabled child is a curse from ancestors or from God, or if you think that he is something that can happen in any family and that these children also have rights and can develop in some way. Spiritual support is knowing that these children also are created in the image of God and we can handle them with care and love (Gunnestad 2010, 2006).

The protective factors work together to create resilience. In cases of receiving a disabled child, all the three groups of protective factors can play a role. The support from family and friends will be important, as well as the thinking about disabilities, prayer and fellowship. Communication skills as well as music and art can be ways to express feelings and get strength. We see that the protective factors create resilience by reducing the effect of risk factors (fear, depression), it can create a positive self-image and cut negative chain reaction and open up for new opportunities:

\subsection{Model of Development of Resilience}

Protective factors:

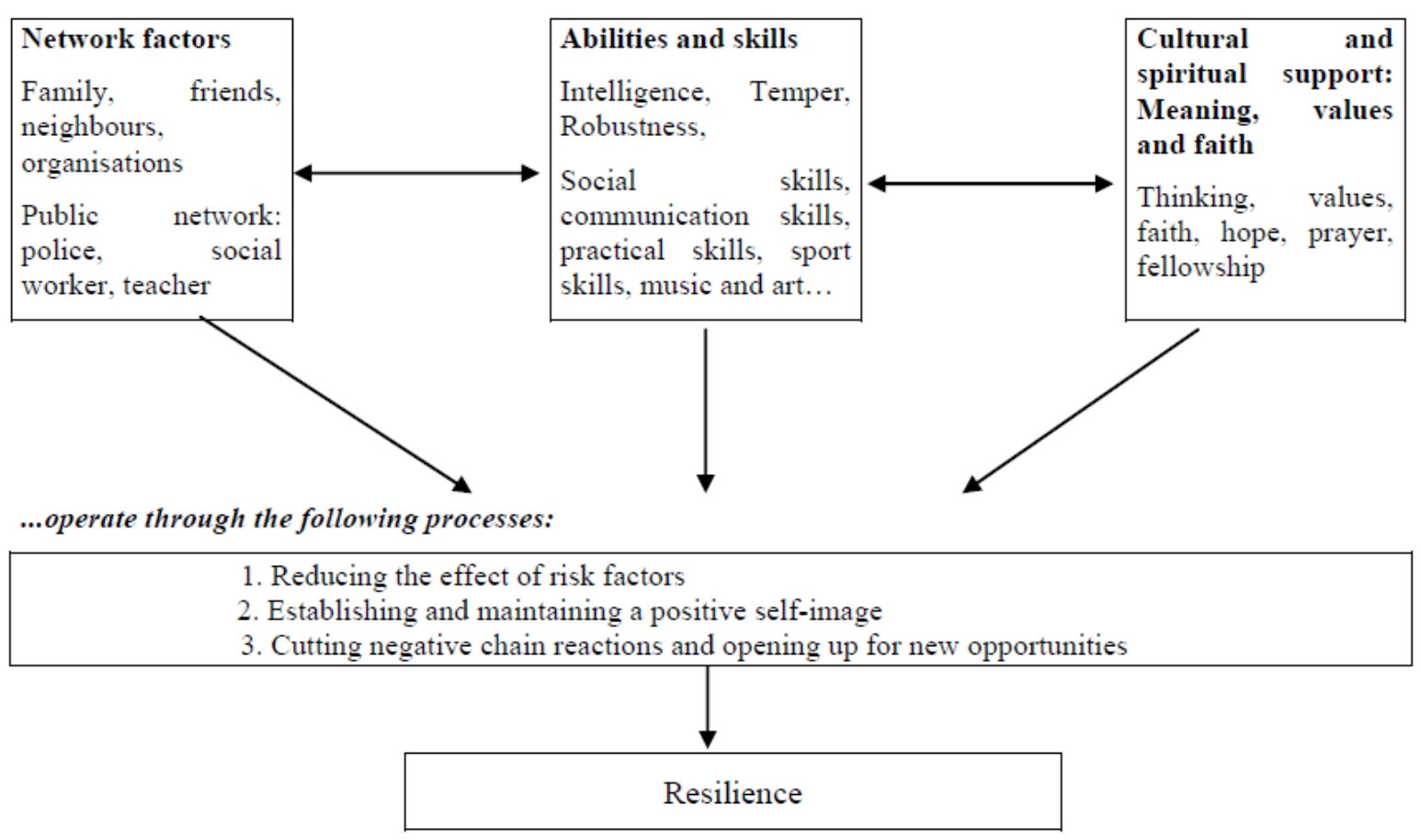

Fig1. Model of development of resilience (adapted from Gunnestad, 2003).

The resilience approach is looking for the resources that is available that can make the person able to cope and handle the situation, to identify the protective factors in each case and to activate them instead of just concentrating on the problems.

This research study is also influenced by resilience conceptual model known as the Walsh's Family Resilience Model (FRM). Walsh (2003) FRM builds on a competence-based and strength-oriented family paradigm that allows a greater understanding of how families display resilience when challenged by adversity.

In Swaziland in each and every family structure, it is common to find children living with disabilities; thus, parents from these structures encounter challenges whereby family resilience is likely to occur. Walsh (2003) outlines three broad categories to conceptualize the manner in which families demonstrate resilience: belief system, organizational patterns and communication processes.

\subsubsection{Family Belief Systems}

Under the family belief there is a subcategory of making meaning out of adversity. This relates to the protective factor "Cultural and existential support". Resilient families view crisis as a shared challenge in contrast to a philosophy of the "tough, rugged individual" getting through adversity. Relationships are extremely important in these families. They believe that by joining hands with family members and others who are significant to the family, they can strengthen their ability to meet challenges. Resilient families see adversity as manageable and meaningful, something that contributes to growth and change across the life cycle of the family (Herman et al, 2009). Parents who 
demonstrate resilient belief systems are able to contextualize the difficulties they have faced, placing those in perspective while being able to draw hope from their challenges and situate them in a larger more global context. How families view their problems and their options can make all the difference between coping, healing and growth or dysfunction and despair (Walsh, 2006a). They make sense of their adversities by asking questions such as how the event happened, why it happened and what can be done (Sixbey, 2005). We see that Walsh here is combining the both the network factor and the cultural and existential factor as resources for these families.

\subsubsection{Maintain a Positive Outlook}

Resilient families hold an optimistic view of life by affirming family strengths and potential in the midst of crisis. Families encourage their members and reinforce a sense of confidence and a "can do" spirit. Parents of children living with disabilities should master the art of the possible by taking stock of the crisis situation and focusing their available energies on making the best of available options. This also implies acceptance of things that are beyond their control. To reinforce hope and optimism, parents can strengthen their familial and social relationships. These relationships can provide encouragement (Sixbey, 2005). Value transcendence and spirituality resilient families find meaning, purpose and connection to something beyond themselves, their members, and their immediate problems. Cultural and religious beliefs provide parents of children living with disabilities with strength, comfort and guidance by providing meaning and purpose to adversity. Resilience can encourage parents of these children to become autonomous, independent, responsible and empathic to approach people and situations with hope, faith and trust. They learn to communicate with others, solve problems, and successfully handle negative thoughts, feelings and behaviours, due to the formal and informal religious affiliation (Gunnestad \& Thwala, 2011; Herman et al., 2009).

\subsubsection{Family Organization and Resources: Flexible}

According to Walsh (2006b) a family that has set rules, roles and boundaries, but is also flexible, is likely to adapt well to change. Parents who have encountered the challenge of having a child with a disability should be flexible and adapt to the change that has occurred in the family. Healthy functioning parents will strive to maintain stability and continuity with the family system while adapting to various life events. While people often refer to "bouncing back" after a crisis, resilience might be seen as bouncing forward. A resilient parent rebound and reorganize in the face of challenge, rather than returning to the way things were done before the crisis.

\subsubsection{Supported by Social and Economic Resources}

Personal ties with friends, extended family members, neighbours, religious organizations and mentors are important to a parent of a child living with a disability in order to communicate with when they need help. Other social resources such as support groups, agencies and community resources are also important. Walsh (2006b) further exposed that financial security is an important aspect of resilience. The loss of wages, due to the onset of a chronic illness or disability to a family member, can increase pile-up stressors. Access to quality services and flexible working conditions helps provide the resources that are necessary to improve the resilience in parents that struggle financially. During times of adversity, resilient parents are able to tap into their social and professional networks for concrete financial, educational and therapeutic resources.

\subsubsection{Communication/Problem-Solving Processes}

Communication that is direct, clear, specific, consistent and honest helps all family members understand the crisis that the parent is facing and encourages him/her to share his/her feelings and opinions with others. This type of communication also sets the stage for a shared process of decision making about how the parent will go forward in the face of crisis (Herman et al., 2009). Parents of children living with disabilities that hide and not discuss adverse life events with their children, with a spouse or other family members can lead to unnecessary anxiety. Family members, who are aware of a problem, without knowing the extent of it, often fear for the worst or imagine that the problem is bigger than it truly is (Walsh, 2006b).

\subsubsection{Use Collaborative Problem-Solving}

Collaborative problem-solving is brainstorming and reaching solutions as a family. This includes involving each family member in goal setting and in mapping out steps to achieve those goals 
(Sixbey, 2005). A resilient parent builds on his/her successes, and learns from failures. They learn to involve their family members in their difficult situations and how to come about in solving those situations. Parents that demonstrate these traits are better able to manage adverse events, promote cohesion, predictability, marital and familial satisfaction. These traits also develop, restore and maintain harmony and balance within the family system (Sixbey, 2005).

The resilience approach makes it easier to see not only the challenges, but also the resources that can be of use to solve a difficult situation. It is important in each situation to identify the protective factors in the network, in the people involved (the parents, the disabled child and others) and the cultural and spiritual resources.

\section{Methodology}

\subsection{Design}

A phenomenological approach was used to explore the experiences of parents of children living with disabilities. A phenomenological approach allows participants to give meaning to their own experiences and to understand and interpret these meanings (Fouché and Schurink, 2011). The design was appropriate for this study which sought to explore experiences, challenges and coping skills of parents of children with disabilities.

\subsection{Participants and Setting}

Participants were a convenience of 48 parents, females $(n=39)$ and males $(n=9)$ were purposively drawn from the three special schools located in the Manzini, Hhohho and Lubombo regions. To qualify to for participation in the study the participants needed to be living with a child with disabilities (see Table 1 for demographics).

Table1. Demographic data of participants according to gender in the three Special Schools

\begin{tabular}{|l|c|c|c|c|}
\hline \multicolumn{1}{|c|}{ Gender } & SP Hhohho & SP Manzini & SP Lubombo & Total \\
\hline Male & 3 & 4 & 2 & 9 \\
\hline Female & 13 & 12 & 14 & 39 \\
\hline Total & 16 & 16 & 16 & 48 \\
\hline
\end{tabular}

Women were more than men probably because females in Swazi culture are viewed as primary caregivers for children. The responsibility of caring for children is left with women while men are out in towns fending for the family.

\subsection{Data Collection and Procedure}

In each institution two focus groups were conducted which comprised of 6 participants making a total of twelve (12) participants in each institution. The remaining 12 parents participated in individual interviews to acquire in-depth information about the experiences and challenges parents faced in raising and nurturing their children with disabilities. In each institution four $(n=4)$ parents which makes a total of twelve $(\mathrm{n}=12)$ parents participated in the individual interviews.

The interview guide was divided into two sections. Section one included the biographic characteristics of the participants which included age, gender, marital status, number of children and educational background. Section two covered the experiences, challenges and resources of parents in raising their children with disabilities. The focus group discussion lasted for 45 minutes -1 hour. A tape recorder was used to capture the participants' responses to the focus group discussions. In addition notes were taken at the same time participants were probed for further relevancy of the responses.

The individual interviews were used to acquire in-depth information about the experiences, challenges and resources of parents in raising and nurturing their children with a disability. The interviews were compared with the focus group interviews, because individual responses cannot be influenced by others like in a group. More time was given to discuss the topic in detail and gain in-depth personal accounts. The researcher audio recorded all interviews to capture the exact words of participants which helped in adding richness to the data being collected.

\subsection{Data Analysis}

Content analysis was used to analyse data where inferences were made by systematically and objectively identifying specified characteristics of messages. The approach by Henning, Van 
Rensburg and Smith (2004) was employed, the approach involves five steps: segment unit of meaning in one or more sentences, label a unit (coding) of meaning in more than a single word, related codes are grouped and categorized, from categories themes are identified, themes are used as base of argument and conclusion. Direct quotations from the participants were extracted, interpreted and discussed.

\subsection{Ethical Issues}

Ethical clearance was obtained from the Ministry of Education to conduct the research. All data were dealt with in a confidential manner. Participation in the study was purely voluntary, and verbal ascent was obtained from participants. Permission to record focus group discussions was obtained from participant prior to conducting the discussions.

\section{RESUltS AND DisCUSSION}

Themes and subthemes which emerged during the thematic analysis are outlined in Table 2. Below:

\begin{tabular}{|l|ll|}
\hline \multicolumn{1}{|c|}{ Themes } & & \multicolumn{1}{c|}{ Categories } \\
\hline 1. Discovering the child's disability & $\bullet$ & Diagnosis \\
& $\bullet$ & Accident \\
& $\bullet$ & Natural cause (pre-mature) \\
& $\bullet$ & Hereditary \\
\hline 2. Reaction after discovering & $\bullet$ & Inability to face new situation \\
& $\bullet$ & Crying \\
& $\bullet$ & Anger \\
& $\bullet$ & Depression \\
& $\bullet$ & Accepted the disability \\
\hline 3. Challenges & $\bullet$ & Lack of freedom on the parents \\
& $\bullet$ & Lack of freedom on siblings \\
& $\bullet$ & Work and careers on parents \\
& $\bullet$ & Concerns about the future of their children \\
& $\bullet$ & Additional workload of caring for the child \\
\hline 5. Exposure and awareness & $\bullet$ & Called by names \\
& $\bullet$ & Society not accepting the children \\
\hline 6. The role of resilience factors resulting to & $\bullet$ & Lacking knowledge of the disability \\
& $\bullet$ & Lacking of training \\
\hline
\end{tabular}

\subsection{Discovering the Child's Disability}

The first question that was asked during the focus group discussion was; "How did you discover that your child has disabilities? Although each participant had his own unique experience, most of them revealed that the discovery occurred after the birth of their children. Most participants suspected disabilities after a delay in the child's motor development, a communication disorder or a delay in communication. One participant disclosed her experience in this way:

When my child was born she appeared as a normal child and was delivered normally without any complications. As she grew I noticed a delay in her motor skill development. She was not holding her head upright. She was also slow in performing her locomotion actions such as sitting, crawling and walking. She was later sent to a neurologist specialist in South Africa who diagnosed her with rare neurological syndrome which he referred to it as mild retardation based on the difference between her normal age and mental age. There was a problem with the functioning of her brain. At the age of 5 her mental growth functioned at the level of a 2-21/2 year's old child. That is how I discovered that our child had a disability.

Another parent revealed that it took her sometime to discover that her child had a disability.

The child kept on repeating classes. She was advised later by the teachers in the normal school to send the child to a special school. Generally, most parents interviewed discovered the disabilities of their 
children after sometime and most of them had to consult doctors or specialists to verify the cause and effects of the disabilities.

\subsection{Reaction after Discovering the Disability}

The participants indicated a variation of reaction related to the difference in the disability of their children. Some experienced shock which rendered them helpless, angry and confused such that they broke in tears where else others eluded that they accepted the condition of their children because of the full support they received from their respective families. It was noted that some parents reacted emotionally in the form of anger, depressing worry, unhappiness and feeling of sadness. One participant had this to say:

I could sense that I was getting disturbed emotionally and mentally after my son was diagnosed with severe autism. My mind was not relaxed in such a way that I was diagnosed with a mild stroke. I felt there was need for me to relax because of the trauma I experienced.

The findings of the study disclosed that some parents showed emotional reactions (Heiman 2002; Gupta \&Singhal, 2004; \&Chimhenga \& Musarurwa, 2011) which revealed that most parents after discovering described reactions such as crying, not eating, cold sweat, trembling, fear, headache, stomach ache and breakdown. That was asserted by another participant who remarked:

Upon, realizing that my girl child was diagnosed with brain malfunction, I could not hold my composure such that I cried hysterical when I heard that my child's mental growth functioned below her normal growth. The doctor who diagnosed my child took it upon himself to make time and provided counseling as he realised that I was affected by the result.

Some participants revealed that it was hard to accept the disability of their children.

They were angry and blamed God to the extent that they made comments on why he allowed that to happen to them and wished that God should take the child. Zelalem (2002) revealed that parents feel angry and search for someone or something to blame. Often anger is directed to God or at the whole world. Anger may be self-directed. From the findings it showed that the participants experienced shock which can be expressed in various ways. The experienced shock rendered the victims helpless, angry, anxious, confused and numb. Other participants expressed their sadness which had been impacted by the condition of their children as discovered.

Some had to reveal that they were concerned about the future of their children under the conditions of their disabilities. One participant remarked in wonder, "I wonder if my son would be in a position to at least drive a car when he grows up".

The comment came after the participant looked at the child and concluded that as he had an intellectual disability chances were slim for him to reach tertiary education. The findings indicated that though a majority $(73 \%)$ of the participants were affected after discovering the disability of their children some had accepted it but they had to undergo the denial process first. One participant highlighted that upon realizing that his son was diagnosed to be autistic it was hard for her to cry because already she had endured seeing the abnormal behaviour in her child. She revealed that she had high hopes that with time her son shall out-grow that behaviour.

One participant remarked:

"There was no need for me to cry as I have seen an abnormal behavior in my child. I was hoping that one day my son will outgrow that behavior" Walsh (2006a) reveals that flexibility in the family's ability to change and adapt to life events, result in adaptation and healthy functioning thus they strive to maintain stability and continuity with the family system while adapting to various life events.

\subsection{Challenges Encountered by the Parents}

Most participants revealed that they had so many challenges which affected them in raising their children living with disabilities.

\subsubsection{Financial Constraints}

They are faced with socio-economic conditions which were caused by the financial constraints. Thus the participants were restricted in their ability to help because of poverty. They were unable to send their children to expensive schools that can rehabilitate them as one participant explained: 
After discovering that our child had autism we decided to enroll him to a rehabilitation centre. The centre was so helpful to the child but the challenges were that we could not afford the required costs per term including transport costs as the boy had to be transported by her mother as he could not go alone due to the behaviour problems. As his mother had to stop working so it was expensive for me to pay the rehabilitation fees and transport fees at the same time.

Even Chimhenga and Musarurwa (2011) on socio-economic conditions revealed that some parents are unable to meet the high travelling expenses to and from the school since such children would need special transport. One participant revealed that she decided to leave her job and take care of their child. When probed why she stated that it was because she could not find a suitable house maid for him as most of them could not afford to care for the child due to their behavioral problems. Chimhenga and Musarurwa (2011) assert that in some homes where house maids were employed, children with disabilities did not receive proper care, especially when their parents would have gone to work the child is sometimes left alone, without food or proper care. That resulted to some parents overprotecting their children and that affected their children's development of independence. Another participant concurred with the notion of leaving the job for the sake of his child living with disabilities. This is what he said:

I was working in one of the sugar companies in the Lubombo Region, before finding a place for the child in one of the special schools in Mbabane. I had to leave my job and a promotion in compromise for my son and we had to re-locate to Mbabane for the sakeof our son. That was a blow to the family especially on the financial aspect because already my wife had left her job to care for our son. Another challenge was that some of my colleagues from work used to ask about the progress of our son. I had to explain that he was in a special school where there were no specific grades as in the normal schools.

The above example shows that having a child with disabilities involved financial constraints as well as the lack of understanding from other people.

\subsubsection{Lack of Freedom for Parents and Siblings}

Another challenge discussed was lack of freedom on the parents and siblings. According to

Green (2007) parents of children with disabilities often raise their children within the context of a powerful societal discourse that devalues disabilities and they are therefore expected to feel emotionally burdened. The participants revealed that they devote more time to child care and spend less time in social activities. They also enjoy less active free time than parents of children without any disability. As a result of the demands of caring, mothers of children with disabilities often report role restriction and limitations in pursuing a career. That was evident to what one participant had to say:

Freedom is limited for the sake of the child. Every time, I had to be at home to welcome her back from school. I am afraid to even leave her alone, because of her mental challenge which is below that of her normal age. Though she can attempt some home chores but I am afraid when she is supposed to boil water. I have feelings that what if water can spill on her, it is really frustrating.

Some participants stated that it was difficult for them to travel with their children because of their disabilities. Each time they did, they drew more attention from the public, which made them feel somehow embarrassed. Later they adjusted gradually due to that they have accepted the disability of their children. The reason behind lack of employment and freedom was the difficulty in finding suitable day-care for their children with disabilities and that made them to stay at home to care for their children.

\subsubsection{Concerns about the Future of their Children}

The findings of the study further revealed that some participants were concerned about the future of their children. They found themselves wondering if their children would be in a position to earn a living because of their intellectual disability. One participant even said he wished his child could outgrow the challenge of autism "akhonekutimelaemhlabeningalelinyelilanga" meaning that being able to be self-sufficient someday. Some parents wished that their children could be able to do practical work so to earn a living. One participant had to comment: "we are growing older and sickly, what would happen to our child when we die?" 
Some of these parents had a feeling that the future of their children was at stake because they had noticed some people with disabilities begging for money in towns. Some parents pondered that how in the future their grown-up children would manage without them. From the participants' remarks it showed that they really encounter some challenges in raising their children with disabilities.

\subsubsection{Stigma and Discrimination}

The finding revealed that the society had not yet accepted the children with disabilities as part of the members in the society who also had needs like all other people. That was disclosed by some participants when they noticed the behaviour of some members of the community. One participant remarked:

My child was once discriminated in church during Sunday school service. I noticed that he was not made to join the other children as they were reciting some verses. Even when the Sunday school choir was called to perform, my child was put aside. Though she could not talk properly but she could have mumbled and followed the other children. I will not forget that day, but I just kept quiet.

The participants revealed that it is so hurting to realize that their children are mocked and discriminated by the society. They felt that due tothe stigma and discrimination, their children's social adjustment resulted to isolation or rejection. The majority of the participants believed that they were the ones most affected by their children's disability in a way that they were always worried about their children's social lives and the amount of their interactions with their peers. That was confirmed by one participant who remarked:

It is hard for my child to interact or socialize with her peers and to even visit relatives. Each time we pay a visit to our relatives we had to explain a lot about here educational background. That made me decides not to go with her when visiting our relatives. It seemed to disturb my relatives as they perceived the child and they turn to sympathize with me.

Some participants revealed that they did not hide their children but they exposed that they felt so ashamed when they recognized their children being discriminated and viewed as a shame in the society. One participant had to say:

One Christmas holiday, we took our child to one of the game reserves in the country (Swaziland). As other children were swimming, when our child with a disability took off her clothes to rush for swimming, everyone stirred at her and even the children who were swimming stopped and looked at her. It was so painful and devastating tous to observe the people looking at her in such a manner.

The treatment and behaviour shown by some community members against children living with disabilities in the communities made the parents of the victims insecure. They even stated that disability is not something one applies for, instead it occurred automatically. From the participants' view, it was evident that they felt so much hurt by the behaviour of the society. So parents of children with disabilities indicated that they felt they had many challenges as compared to the parents of children without disabilities.

\subsubsection{Parents' Lack of Knowledge and Awareness}

Most of the participants agreed that they lacked simple knowledge, ideas and awareness about the disabilities of their children, They revealed that they were unable to recognize the disabilities of their children on time, that was due to lack of awareness. One participant remarked:

I did not know that my child had an intellectual disability. That is why it took some years for me to realize that the child needs to be sent to a special school.

The protective factors by Gunnestad (2003) on knowledge of parenting and their child development, stated that having accurate information about raising young children with disabilities and appropriate expectations for their behaviour helps parents better understand and care for such children. The responses were in line with what Chimhenga et al. (2011) revealed that in his study when parents were interviewed on knowledge about cerebral palsy they indicated that they did not know the causes, effects and prevention of the cerebral palsy. Some decided to consult traditional healers and were 
made to believe that the disability was associated with witchcraft or evil spirits. Olsson, (2008) emphasizes the importance of parents searching for information about the disabilities of their children. Having accurate information about how they could raise these children and appropriate behaviour expected could help them better understand and care for their children.

\subsection{Protective Factors - Coping Strategies}

\subsubsection{Family Support}

The findings of this study revealed that most (68\%) participants were from nuclear families, they had moved out of the extended family settings. However some had to reveal that their extended family members such as grandparents and the in-laws were of great help to them. If they did not involve the extended family members they would not have accepted the disability of their children. Some participants even revealed that they would not have been in a position to overcome some of the problems and difficulties if it would not have been for the support of their families. Few of them revealed that their friends and colleagues were their source of strength that supported them holistically to enable to pass on the denial stage.

Some of the participants indicated that their children were of great help and supportive to their brothers or sisters with disabilities. One participant remarked "My family members are a source of strength; they helped me a lot and support me and my husband." Another participant concurs.

Our children are so supportive to us and their brother. They accepted him and enjoy playing with him, though sometimes it is for a while due to the disability of their brother. That also helps my wife to have a free time to take care of her needs.

Similarly Walsh (2003) reveals that parents tried to maintain their routine life, sometimes drawing on or even initiating support from nuclear family members, grandparents and other relatives.

The findings revealed that most participants preferred to share their experiences withtheir family members, relatives and friends. They felt relieved after talking to someone about the disabilities of their children. They received help which made them understood the behaviours and the disabilities of their children. That helped them to accept the condition of their children. As one participant remarked:

When our boy reached 3 years of age we could not send him to a pre-school because he was violent and we did not know what the cause of such behaviour was. What helped us was to contact another Christian lady in church and we stated the behaviour of our child, she helped us a lot and disclosed the kind of a disability that is shown by children with such behaviour as she had one of the kids.

\subsubsection{Counselling}

Walsh (2003) says counselling is a central process in human coping of many situations in life. So, receiving counselling can provide them with clear understanding of the disability of their children, and how to live with that situation. It was discovered in the discussions that some parents undergo counselling from the therapists and some paediatricians when they discovered the disability of their children, however most parents did not receive any counselling. One of the participants who received counselling had to say:

When we sent our child to the family doctor in South Africa who diagnosed her with the rare neurological syndrome, after making me aware of our child's condition, he took his time and provided me with proper counselling. That eased the pain of discovering the disability.

One participant had this to say:

As a parent who is not working, I am so grateful to the Social and Welfare Department which decided to take of my children and pay the school fees. The workers constantly visit us to offer assistance and discuss about the condition of my child that helps us emotionally.

It is important that parents understand the situation and the behaviour of their children and also that they have some guidance as to how they should relate and teach their children in relation to everyday life. 


\subsubsection{Spiritual Resources}

Furthermore, the participants stated that what made them cope with the situation of having a child with a disability was to attend church services or going to church and prayer or to be prayed for. This is not surprising as Swaziland is a Christian country and people are taught Christian values early in life. This also confirms the findings by (Walsh, 2003) inwhich Cultural and religious beliefs provided parents of children living with disabilities with strength, comfort and guidance by providing meaning and purpose to adversity. In a number of international studies one has found that prayer,fellowship in church and examples from the Bibleis reported as one of the protective factors in resilience(Gunnestad \& Thwala, 2011; Masten, 2014; Werner \& Smith, 2003). That was confirmed by one participant who had this to say:

As Christians we get the strength from God. When we first realized the problem with the child, we asked God what did we do wrong in order to give us such a child yet he is a first born. We believed that it was an attack from the devil and that God will miraculously do something with the child. We have accepted the child that we still trust God in prayer that something wonderful will happen.

Another parent remarked:

I am a proud parent; I believe that God was trying to teach me to be a humbled person. Thus God had a plan and trusted me that I could help the child grow.

This showed that most (73\%) participants shared their feelings or thoughts about their children's disability with the people to whom they felt most close, had the greatest confidence in or from whom they expected understanding and from whom they received strength, comfort and guidance. The theoretical framework according to Walsh (2003) revealed that resilient families have a network of people (family members, friends, and neighbours) and organizations that can serve as their lifelines during challenging times. This network provides assistance (information, concrete services), emotional support and connection to the larger community. She further exposed that financial security is an important aspect of resilience. So, during times of adversity, resilient parents are able to tap into their social and professional networks for concrete financial, educational and therapeutic resources. The finding is in line with Walsh model in which he states personal ties with friends, extended family members, neighbours, religious organizations and mentors are important to a parent of children with disabilities as they act as protective factors. The findings showed that Swazi's handle new situations through trusting God and prayer which act as a protective factor in resilience.

\section{CONCLusions}

The experiences encountered by parents of children living with disabilities are diverse due to the different disabilities of their children. It has been established however, that most parents had similar experiences in discovering their children's disabilities. The parents were affected physically, emotionally and psychologically. We found that it is essential that health personnel and teachers are able to give counselling to parents of children with disabilities. The findings make it crystal clear that parents are faced with so many challenges in raising their children living with disabilities such as; financial constraints, limitation in career pursuing, lack of freedom on the parents and siblings, stigmatisation of the child and means of providing guidance as they do not have enough information on how to raise their children. We found that the protective factor of network and support from family and friends were essential. Also the support from the cultural and spiritual field is important. Parents need information about the disability, and spiritual support has also seen to be important for parents to be able to accept the condition of the child and to live with and care for the child in a good way.

\section{RECOMMENDATIONS}

Parents of children living with disabilities in Swaziland need some counseling after the diagnosis of their children in order for them to be able to cope with the stresses that come with the discovery of their children's disability and to accept them no matter what the condition. Parents need to form "parents to parents support groups" for the different disabilities in order to share ideas as they face their situations and to help one another with strategies on how to cope with the conditions of their children. 


\section{REFERENCES}

[1] Blew, H., \& Kenny, G. (2006). Attention deficit hyperactivity disorder. The current debate and neglected dimensions.Journal of Child Health care, 251-263.

[2] Chimhenga, S., \&Musarurwa, C. (2011). Educating children with special needs-the African context: Retrieved from www.SAVAP.org.pk

[3] David M, Sutton CD 2004. Social Research. The Basics. London: Sage Publishers.

[4] Dobson, B., Middleton, S., \&Beardworth, A. (2001).The Impact of childhood disability on family life. New York: Joseph Rowntree Foundation.

[5] Fergus, S.,\& Zimmerman, M.A.(2005). Adolescent resilience: A framework for understanding healthy development in the face of risk. Annual Review of Public Health, 26:399-419.

[6] Fouché, C.B., \&Schurink, W. (2011). Qualitative research designs. In A.S. de Vos, H. Strydom, C.B.Fouché, \& C.S.L. Delport (Eds.), Research at grassroots: For the social sciences and human service professions ( $4^{\text {th }}$ ed., pp. 307-327) Pretoria, South Africa: Van Schaik.

[7] Green, S.E. (2007). We are tired not Sad: Benefits and burdens of mothering a child with a disability. Social Science and Medicine, 64, 150-163.

[8] Gunnestad, A., \& Thwala, S. K. (2011). Resilience and religion in children and youth in Southern Africa. International Journal of Children's Spirituality, 16(2), 169-185. doi:10.1080/1364436X.2011.580726

[9] Gunnestad, A. (2010). International perspectives on child abuse and resilience. Nordic Studies in Education, no. 1, 2010.

[10] Gunnestad, A. (2006). The Child - Vulnerable and Resourceful. Report from the $8^{\text {th }}$ Network Conference, Manzini, Swaziland.

[11] Gunnestad, A. (2003). Report from $5^{\text {th }}$ network conference. A child's right in early Childhood education in Africa and Norway. Queen Maud's College of Early Childhood Education.

[12] Gupta, A., \&Singhal, N. (2004).Positive perceptions in parents of children with disabilities, Asia Pacific Disability.Rehabilitation Journal. 15. (1).

[13] Heiman, T. (2002). Parents of children with disabilities: resilience, coping and future expectations. Department of education and psychology. Journal of developmental and physical disabilities, 14. (2).

[14] Herman, P., Peterson, P., \&Schaaf, J. (2009).Family Living Educators, UW-Extension. 2009. Resource.

[15] Lewis and Doorlag .(2006). Teaching Special Students in General Education Classrooms. Upper Saddle River: Pentice Hall.

[16] Mampane, R., \&Bouwer, C. (2011). The influence of township schools on the resilience of their learners. South African Journal of Education, 31(1):114-126.

[17] Masten, A.S.(2001). Ordinary magic: Resilience processes in development. American Psychologist, 56(3):227-238.

[18] Masten, A. S. (2014). Ordinary Magic. Resilience in Development. New York / London: the Guilford Press.

[19] Özlem Ögtem-Young, (2018) Faith Resilience: Everyday Experiences. Societies, 2018, 8(1), 10; https://doi.org/10.3390/soc8010010

[20] Richardson, G.E.(2002). The Metatheory of resilience and resiliency. Journal of Clinical Psychology, 58(3):307-321.

[21] Scorgie, A., \&Sobsey.B.(2000), Roecher Institute Beyond the limits.Mothers caring for children with disabilities. Children and Family Series, North York, Canada: Rocher Institute; 2000. 1-40.

[22] Sixbey, M.T. (2005). Development of the family resilience assessment scale toidentify family resilience constructs. (Doctoral dissertation, University of Florida).

[23] Theron, L.C.,\&Theron, A.M.C.(2010).A critical review of studies of South African youth resilience, 19902008.South African Journal of Science, 106:252.

[24] Walsh, F. (2003).Normal Family Processes: Growing diversity and Complexity (3 ${ }^{\text {rd }}$ ed.) Newyork. Guilford Press.

[25] Walsh, F. (2006a). Changing families in a changing world: reconstruction family normality.In: Normal family process: Growing Diversity and Complexity. $\left(4^{\text {th }} \mathrm{ed}\right)$.

[26] Walsh, F. (2006b). Strengthening Family Resilience. ( $2^{\text {nd }}$ ed).Guilford Press.Newyork

[27] Welman C, Kruger F, Mitchell B (2005). Research Methodology (3rd Ed). Cape Town: Oxford University Press Southern Africa.

[28] Werner, E. E., \& Smith, R. S. (2003). Att växa mot alla odds : från födelse till vuxenliv. Stockholm: Svenska föreningen för psykisk hälsa. 
[29] Werner, E. E. \& Smith, R. S. (1992).Overcoming the Odds. High risk children from Birth to Adulthood. Cornell University Press, Ithaca and London.

[30] Zilalem, F. (2002).The attitudes of parents towards their blind children: Acase study. Bahir Dar Town: Addis Ababa University.

[31] Zindi, F. (1997).Psychology for the classroom. Visc, Harare: College press

\section{AUTHORS' BiOgRAPHY}

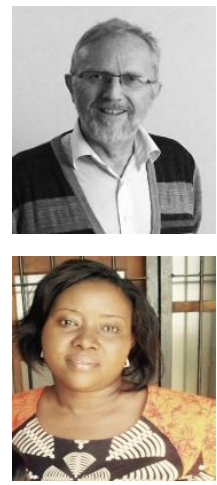

Arve Gunnestad is a Professor at Queen Maud University College currently works at the Special needs department, Queen Maud University College of Early Childhood Education. Arve does research in Comparative Education, Educational Leadership and Didactics. His current project is 'Value learning in Early childhood centres in Norway'.

Dr S'lungile Kindness Thwala is a Senior lecturer and the Head of Department at University of Eswatini under the Department of Educational Foundations and Management. She holds a PhD in Psychology of Education and MEd in Special Educational Needs. Her research interests; Special and Inclusive education, Early childhood Education, resilience and psychosocial support

Mrs Iren N. Dludlu is a lecturer at William Pitcher Teachers Training College. She holds a Masters in Guidance and Counselling and B Ed. Primary degree from the University of Eswatini

Citation: S, K. Thwala. "Parents of Children with Disabililties in Swaziland Challenges and Resources in a Resilience Perspective" International Journal of Humanities Social Sciences and Education (IJHSSE), vol 5, no. 12, 2018, pp. 28-40. doi: http://dx.doi.org/10.20431/2349-0381.0512004.

Copyright: (C) 2018 Authors. This is an open-access article distributed under the terms of the Creative Commons Attribution License, which permits unrestricted use, distribution, and reproduction in any medium, provided the original author and source are credited. 